\title{
Peròxid d'hidrogen, catalasa i cinètica química
}

Josep Corominas

Departament de Ciències, Escola Pia de Sitges

jcoromi6@xtec.cat

L'enzim catalasa està present en molts vegetals. Amb ell és fàcil de fer diversos experiments que permetin estudiar com actua i controlar els factors que regulen la cinètica d'una reacció catalitzada.

Paraules clau: cinètica, enzim, velocitat de reacció

\section{Introducció}

La catalasa és un enzim que es troba en organismes vius i catalitza la descomposició del peròxid d'hidrogen, $\mathrm{H}_{2} \mathrm{O}_{2}$, en oxigen, $\mathrm{O}_{2}$, i aigua.

La reacció global és:

$$
\mathrm{H}_{2} \mathrm{O}_{2}(\mathrm{aq}) \rightarrow \mathrm{H}_{2} \mathrm{O}(\mathrm{I})+1 / 2 \mathrm{O}_{2}(\mathrm{~g})
$$

El peròxid d'hidrogen, vulgarment "aigua oxigenada", és un residu del metabolisme cel-lular de molts organismes vius. En ser una substància tòxi- ca, ha de transformar-se ràpidament en compostos menys perillosos. Per a això hi actua l'enzim catalasa, que catalitza la seva descomposició en aigua i oxigen. El mecanisme complet de la catalasa no es coneix, tanmateix la reacció química es produeix en dues etapes (Boon, Downs i Marcey, 2007):

$$
\begin{gathered}
\mathrm{H}_{2} \mathrm{O}_{2}+\mathrm{Fe}(\mathrm{III})-\mathrm{E} \rightarrow \mathrm{H}_{2} \mathrm{O}+\mathrm{O}=\mathrm{Fe}(\mathrm{IV})-\mathrm{E} \\
\mathrm{H}_{2} \mathrm{O}_{2}+\mathrm{O}=\mathrm{Fe}(\mathrm{IV})-\mathrm{E} \rightarrow \mathrm{H}_{2} \mathrm{O}+\mathrm{Fe}(\mathrm{III})-\mathrm{E}+\mathrm{O}_{2}
\end{gathered}
$$

on Fe-E representa el nucli de ferro del grup hemo unit a l'enzim.

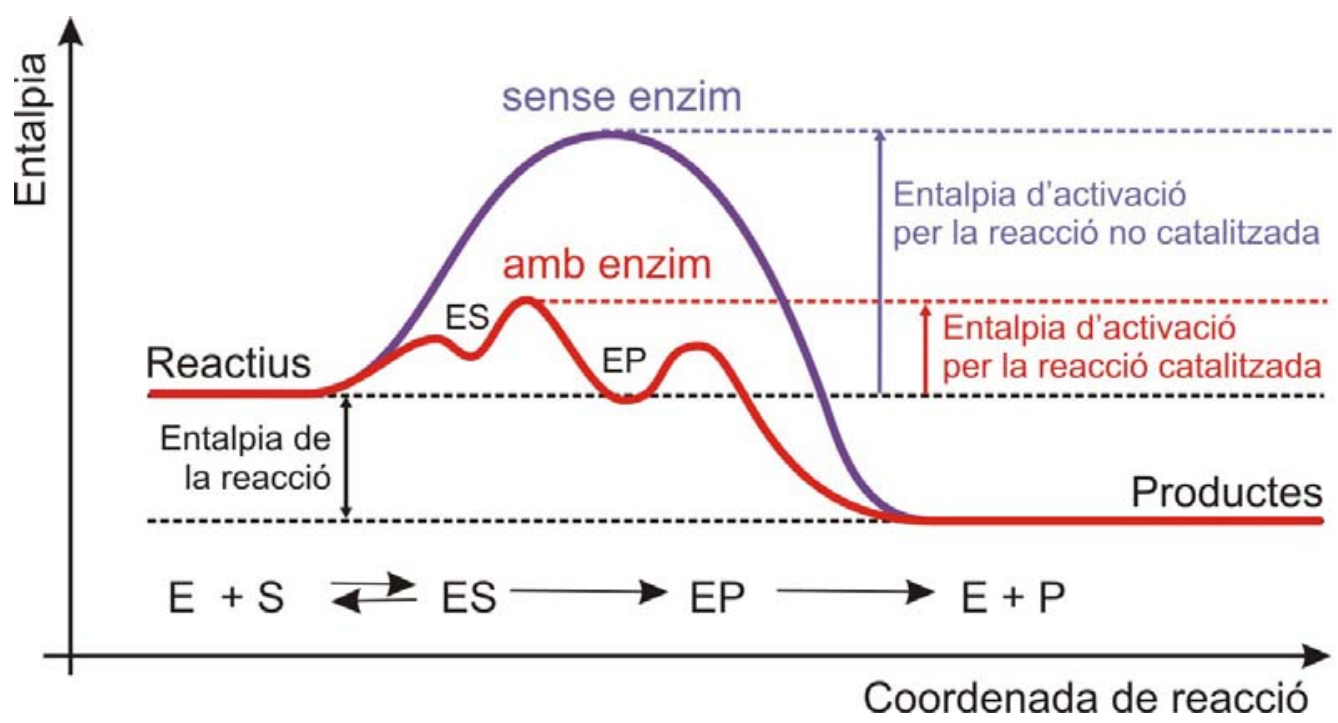

Figura 1. Manera com un enzim actua de catalitzador i proporciona un camí de menor energia d'activació. (ES: enzim-substrat; EP: Enzim-productes de la reacció). 
L'acció dels enzims s'explica pel fet de rebaixar l'energia d'activació dels reactius en les reaccions catalitzades. Les molècules que reaccionen en una reacció catalitzada tenen una menor energia quan xoquen de la que tindrien si no actués un catalitzador.

Dit d'una altra manera, l'energia o entalpia d'activació és menor, tal com es pot veure en la fig. 1.

És molt fàcil de disposar d'aquest enzim, doncs està present en els llevats, però també en molts vegetals. A més a més, la seva acció provoca una reacció on la formació d'un gas es pot observar fàcilment i mesurar-ne el volum generat o l'augment de pressió si la reacció té lloc en un recipient a volum constant (Barbé i Vives, 2003). Aquesta reacció tant es pot treballar des del punt de vista de l'acció enzimàtica com de la cinètica química.

\section{Objectius}

- Observar com es descompon l'aigua oxigenada en contacte amb un catalitzador com la catalasa present en els vegetals i en els llevats.

- Investigar els factors dels quals depèn l'acció de l'enzim catalasa.

\section{Planteig del problema}

L'acció de l'enzim implica que la velocitat de la reacció de descomposició del peròxid d'hidrogen canviarà segons les condicions.

La velocitat d'una reacció és una magnitud que descriu la rapidesa amb què els reactius es converteixen en productes.

\section{Qüestionari per a l'alumnat}

1. Si volem seguir l'evolució de la reacció, fixant-nos en el gas oxigen desprès, quina seria la millor manera de fer-ho? Proposa un diagrama del muntatge, tenint en compte que pots seguir la producció de gas amb un sensor de pressió.

2. Per arribar a tenir una taula de dades i una gràfica de l'evolució de la reacció, quina seria la variable independent a mesurar? Quina seria la variable dependent? Quin aspecte suposes que ha de tenir una gràfica amb aquestes magnituds?

3. Quines són les magnituds que cal mantenir invariables?

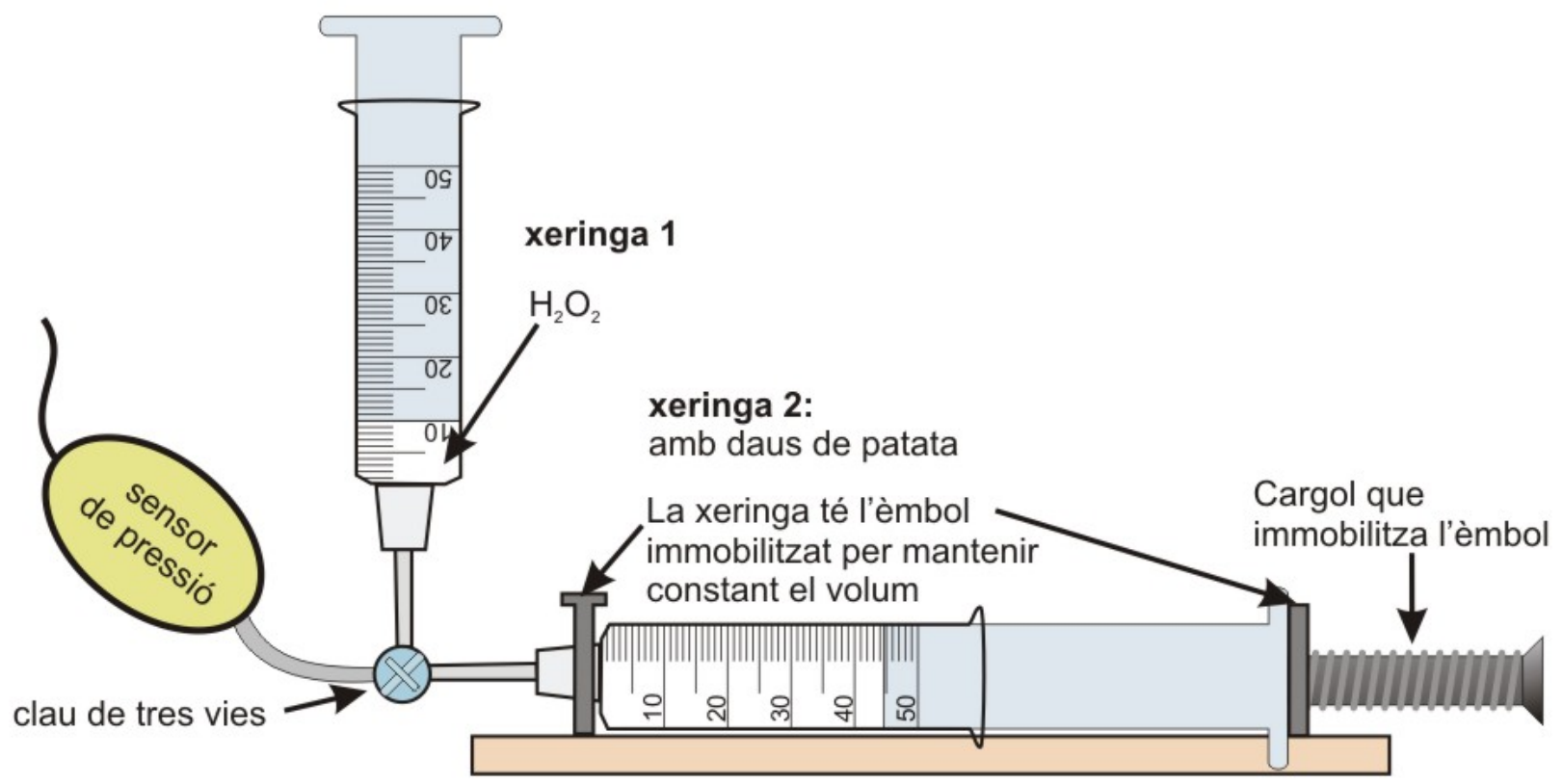

Figura 2. Diagrama del muntatge proposat. 
Per determinar-la, cal mesurar al cap de diferents temps la concentració d'un dels components o una propietat física que hi estigui relacionada, per exemple la pressió o el volum, si es desprèn un gas.

\section{Proposta de muntatge}

El muntatge proposat (figs. 2 i 3) utilitza un sensor de pressió de l'equipament Multilog, una clau de tres vies (lauer-lok) i dues xeringues de $60 \mathrm{~mL}$ amb possibilitat de roscar-hi la clau de tres vies i el sensor de pressió.

La xeringa on tindrà lloc la reacció té l'èmbol immobilitzat.

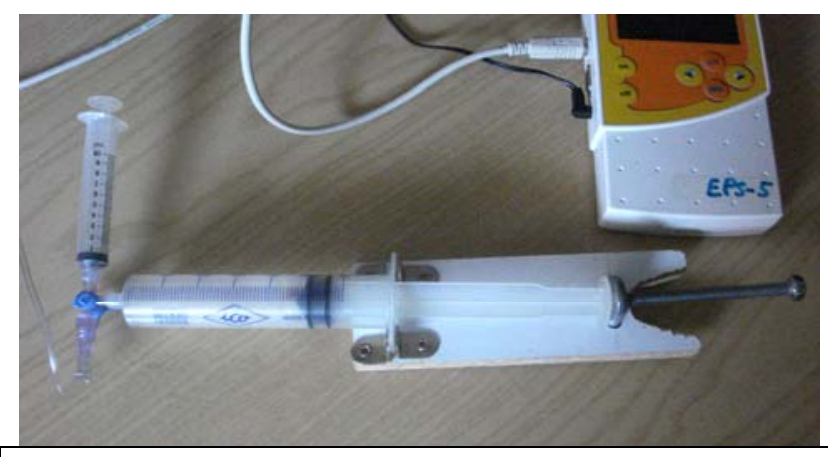

Figura 3. Fotografia del muntatge.

La fig. 4 mostra una manera de construir un dispositiu per immobilitzar l'èmbol.

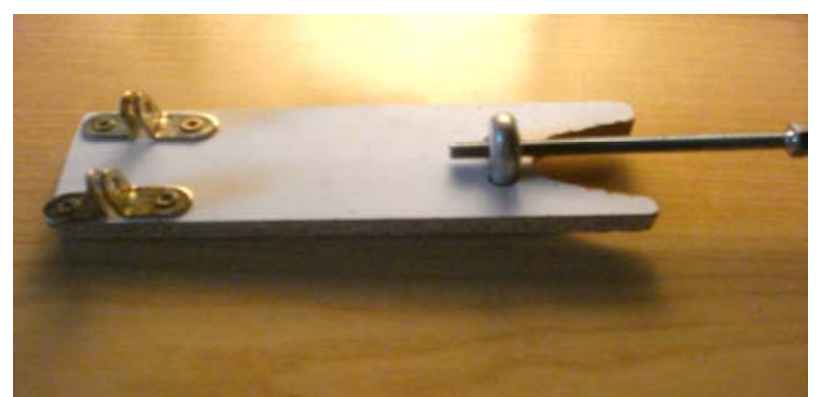

Figura 4. Dispositiu per immobilitzar l'èmbol de manera que la reacció transcorri a volum constant.

\section{Realització pràctica}

- Muntar les dues xeringues de manera que quedin en posició horitzontal a la taula de treball. El tub transparent del sensor de pressió s'ha de collocar de manera que quedi vertical respecte de les xeringues, això evitarà que entri líquid en el tub.
- Es comença per $\mathrm{H}_{2} \mathrm{O}_{2}$ al $3 \%$ (10 volums), que és la que es troba en les farmàcies. Desmuntar la xeringa 1 (vegeu fig. 2) i succionar $10 \mathrm{~mL}$ de solució d' $\mathrm{H}_{2} \mathrm{O}_{2}$ al $3 \%$.

- Uns tres o quatre daus de patata d'uns $0,5 \mathrm{~cm}$ de costat són suficients com a catalitzador. Es posen dins la xeringa que ha de quedar immobilitzada. Deixar l'èmbol de la xeringa en la posició de $40 \mathrm{~mL}$ de manera que quan s'injectin 10 $\mathrm{mL}$ d'aigua oxigenada, l'èmbol es desplaci fins els $50 \mathrm{~mL}$ i topi amb el cargol que l'ha de mantenir fixa.

\section{Configuració del programa Multilog}

Freqüència de captació:

cada 10 segons

Temps de captació de dades: continu

- Connecteu les xeringues amb la clau de tres vies i aquesta amb el sensor de pressió.

- Assegureu-vos que sabeu controlar la posició de la clau de tres vies: pot comunicar les dues xeringues o pot comunicar la xeringa 2 amb el sensor de pressió.

- Engegueu la captació de dades. Poseu la clau de tres vies en posició de comunicar la xeringa $1 \mathrm{amb}$ la $2 \mathrm{i}$ injecteu els $10 \mathrm{~mL}$ de $\mathrm{H}_{2} \mathrm{O}_{2}$. Immediatament canvieu la posició de la clau, de manera que comuniqui la xeringa 2 amb el sensor de pressió. Procureu que el tub transparent del sensor de pressió estigui en posició vertical per evitar l'entrada de líquid al tub del sensor.

- Deixeu passar el temps i aneu observant la gràfica de la pressió en funció del temps.

- Quan hagi passat prou temps i el gràfic s'hagi estabilitzat, atureu la captació de dades.

\section{Anàlisi de dades i qüestionari per l'alumnat}

- Quina és la variable independent i la variable dependent del vostre experiment? Quines magnituds heu mantingut constants?

- Què ha passat dins la xeringa 2? Com es pot interpretar?

- És continu l'augment de pressió? O bé hi ha una estabilització del gràfic al cap d'un cert temps? Com es podrien interpretar els resultats?

- Els resultats obtinguts estan d'acord amb la vostra predicció? 


\section{Treballant l'aspecte de la cinètica de la reacció}

La gràfica obtinguda marca l'evolució de la pressió (gas oxigen generat) en funció del temps.

La velocitat de la reacció és la derivada de la concentració d'un component de la reacció (l'oxigen en aquest cas) respecte del temps. Per calcular la velocitat de reacció en un instant cal trobar la tangent a la corba en el punt corresponent a l'instant de temps que interessi. La figura 5 mostra com trobar la velocitat de reacció per l'instant $1200 \mathrm{~s}$ (Caamaño i Corominas, 2002).

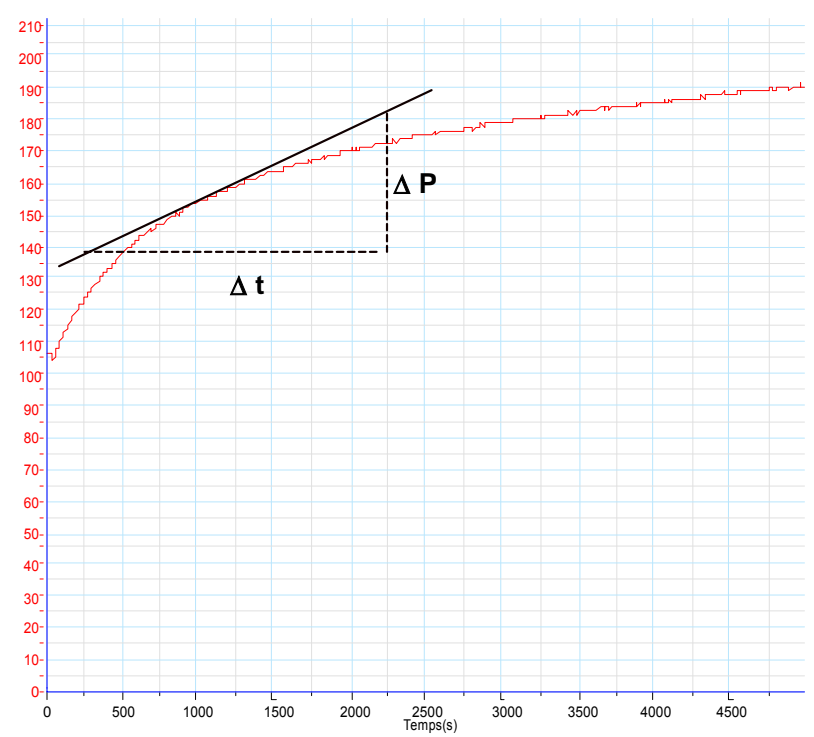

Figura 5. Com trobar la velocitat de la reacció quan $t=1200 \mathrm{~s}$, traçant la tangent $\mathrm{i}$ calculant-ne el pendent.

L'experiment és llarg: com a mínim una hora de captació de dades (pot ser fins a 1,5 hores), més el temps de planificació i de muntatge de l'experiment. Per tant, convé distribuir-ho en dues sessions: la primera per planificar, muntar i engegar la captació de dades. La segona sessió (un altre dia), per analitzar els resultats obtinguts i treure'n conclusions.

Amb uns quants daus de patata i $10 \mathrm{~mL}$ d'aigua oxigenada al 3\% la pressió s'estabilitza en unes tres hores, augmentant en més de $110 \mathrm{kPa}$ respecta de la pressió inicial (fig. 6).

Per variar les condicions es dilueix l'aigua oxigenada a l' $1,5 \%$ (5 mL de $\mathrm{H}_{2} \mathrm{O}_{2}$ i $5 \mathrm{~mL}$ d'aigua destil.lada).

També es pot estudiar el factor temperatura: és suficient deixar una bombeta encesa a uns $10 \mathrm{~cm}$ de la xeringa on té lloc la reacció.

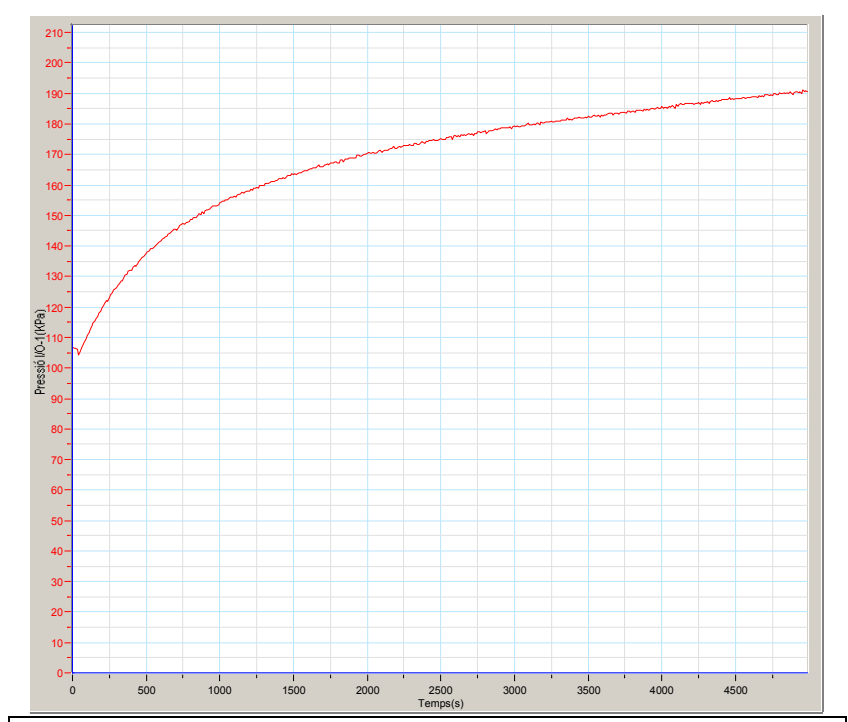

Figura 6. Gràfica pressió-temps obtinguda amb aigua oxigenada al $3 \%$.

Una investigació sobre la presència d'aquest enzim en diversos vegetals i llevats, així com de quina manera afecten els factors de temperatura $i$ de $\mathrm{pH}$ a l'acció enzimàtica pot servir com a proposta d'un treball de recerca.

\section{Informació addicional sobre la catalasa}

L'ús més important de la catalasa és per eliminar restes de peròxid d'hidrogen, un producte altament oxidant emprat en la industria tèxtil per blanquejar, en l'esterilització d'envasos alimentaris, en l'esterilització de formatges i en alguns casos en la neteja de lents de contacte. En tots aquest casos la catalasa s'encarrega de descompondre les possibles restes d' $\mathrm{H}_{2} \mathrm{O}_{2}$ que hi podrien quedar.

Estudis molt recents (Hitti, 2009) assenyalen que les canes i cabells grisos podrien tenir l'origen en una deficiència de catalasa, la qual no podria descompondre el peròxid d'hidrogen format en el metabolisme cel-lular produint-se per tant l'efecte de blanquejar el cabell.

\section{Bibliografia}

Barbé, A; Vives, V (2003). L'activitat de la catalasa als llevats. Treballs pràctics de biologia. Batxillerat. Barcelona: Departament d'Educació.

http://www.xtec.es/cdec/recursos/pdf/nntt_b/pdf/ catalasa.pdf

Boon, E.M., Downs, A., Marcey, D. (2007). Proposed Mechanism of Catalase. Catalase: $\mathrm{H}_{2} \mathrm{O}_{2}$ : $\mathrm{H}_{2} \mathrm{O}_{2}$ Oxidoreductase: Catalase Structural Tuto- 
rial.

http://biology.kenyon.edu/BMB/Chime/catalase/f

ra-

mes/cattx.htm\#Proposed\%20Mechanism\%20of $\% 20$ Catalase.

Caamaño, A., Corominas, J. (2002). Treballs pràctics de Química. Batxillerat. Materials de formació. Barcelona: Departament d'Educació.

http://www.xtec.es/cdec/recursos/pdf/TPQ/30_re ac.pdf

Hitti, M. (2009). Why Hair Goes Gray. Health News. 